\section{Anterior arytenoid cartilage dislocation, a rare complication of esophagogastroduodenoscopy}

Arytenoid cartilage dislocation is a rare complication after tracheal intubation, occurring in less than $0.1 \%$ of cases [1, 2]. Here we present a case of arytenoid cartilage dislocation following esophagogastroduodenoscopy (EGD). A man in his sixties underwent EGD as a follow-up examination after endoscopic treatment for early gastric cancer. The examination was carried out with a standard endoscope (GIFH260, Olympus, Tokyo, Japan), under conscious sedation with midazolam ( $3 \mathrm{mg}$ ) and pethidine chloride $(35 \mathrm{mg})$, and was completed uneventfully. After a 1 -hour rest in the recovery unit, the patient developed aphonia without any throat pain. Following treatment with dequalinium chloride troches, the patient still had persisting hoarseness and difficulty swallowing 4 days later. Laryngoscopy showed anterior dislocation of the left arytenoid cartilage, with a flaccid and fixed left vocal cord $(\bullet$ Fig. 1). Fiberscopic reduction was carried out as an ambulatory procedure, under local anesthesia, and reposition was confirmed on the following day ( $\bullet$ Fig.2). The dysphonia and vocal cord movement improved gradually over the next 2 weeks ( $\odot$ Fig. 3 ).

Arytenoid cartilage dislocation presents with hoarseness, dysphagia, throat pain, and stridor. Direct visualization of cricoarytenoid dislocation by laryngoscopy is useful, and early recognition directly impacts treatment success [3]. Only one case of arytenoid dislocation following EGD has been reported in the literature [4], and the incidence of this rare complication is unknown. Endoscopists should be mindful of arytenoid dislocation occurring as a complication after EGD.

Endoscopy_UCTN_Code_CPL_1AH_2AB

\section{Competing interests: None}

N. Kakushima ${ }^{1}$, K. Hotta ${ }^{1}$, M. Tanaka ${ }^{1}$, N. Kawata ${ }^{1}$, H. Sawai ${ }^{1}$, K. Imai ${ }^{1}$, T. Takao", M. Takao', K. Takizawa', H. Matsubayashi ${ }^{1}$, Y. Yamaguchi ${ }^{1}$, H. Ono ${ }^{1}$, T. Onitsuka ${ }^{2}$

${ }^{1}$ Division of Endoscopy, Shizuoka Cancer Center, Shizuoka, Japan

2 Division of Head and Neck Surgery, Shizuoka Cancer Center, Shizuoka, Japan

\section{References}

1 Yamanaka H, Hayashi Y, Watanabe $Y$ et al. Prolonged hoarseness and arytenoid cartilage dislocation after tracheal intubation. Br J Anaesth 2009; 103: 452 - 455

2 Szigeti C, Baeuerle J, Mongan P. Arytenoid dislocation with lighted stylet intubation: Case report and retrospective review. Anesth Analg 1994; 78: 185-186

3 Sataloff RT, Bough ID, Spiegel JR. Arytenoid dislocation: diagnosis and treatment. Laryngoscope 1994; 104: 1353-1361

4 Afonso A, Woo P, Reed A. Arytenoid dislocation following upper gastrointestinal endoscopy. Endoscopy 2011; 43: E368

\section{Bibliography}

Dol http://dx.doi.org/

10.1055/s-0032-1310072

Endoscopy 2012; 44: E363

(c) Georg Thieme Verlag KG

Stuttgart · New York

ISSN 0013-726X

Corresponding author

\section{N. Kakushima}

Division of Endoscopy

Shizuoka Cancer Center

1007 Shimonagakubo

Nagaizumi

Suntogun

Shizuoka 411-8777

Japan

Fax: +81-55-989-5692

kakushin-tky@umin.ac.jp

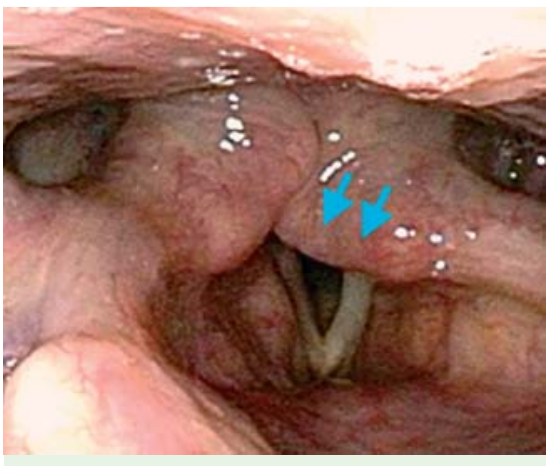

Fig. 1 Laryngoscopic view of the anterior dislocation (blue arrows) of the left arytenoid cartilage four days after esophagogastroduodenoscopy (EGD) in an older man.

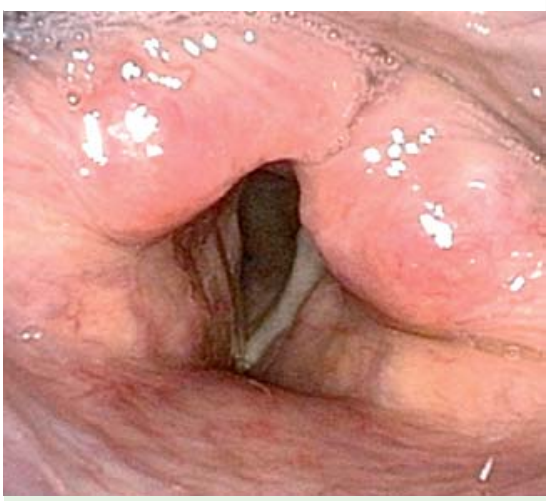

Fig.2 The repositioned arytenoid cartilage 1 day after fiberscopic reduction.

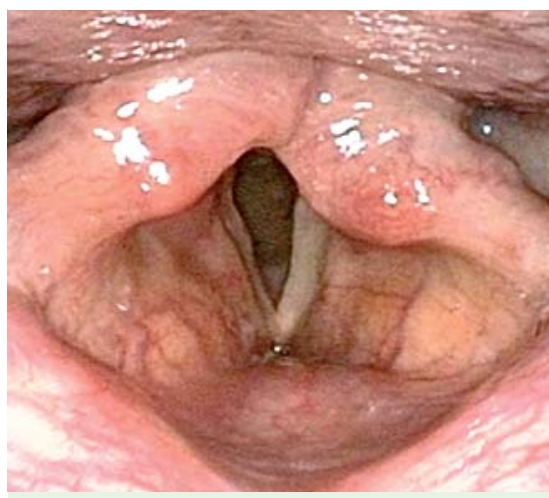

Fig. 3 There was gradual improvement in the dysphonia and vocal cord movement over the next 2 weeks. 